\title{
Experiences of romantic relationships and desires to marry and have children among youth in a low-fertility society
}

\author{
Mayumi Ohnishi ${ }^{1}$, Kazuyo Machiyama ${ }^{2}$, Mika Nishihara ${ }^{1}$, Miho Sato ${ }^{3}$, and Akiko Matsuyama ${ }^{4}$ \\ ${ }^{I}$ Department of Health Sciences, Nagasaki University Graduate School of Biomedical Sciences, Japan \\ ${ }^{2}$ London School of Hygiene and Tropical Medicine, UK \\ ${ }^{3}$ Nagasaki University Graduate School of Tropical Medicine and Global Health, Japan \\ ${ }^{4}$ Tsuda University, Japan
}

\begin{abstract}
Introduction: This study aims to explore experiences of romantic relationships and to examine determinants of desires to marry and have children in the future among Japanese university students.

Methods: A cross-sectional study was conducted among undergraduate students of A University, located in the capital city of a Japanese prefecture, using an anonymous self-administered and structured questionnaire developed by an online survey software. Results: A total of 815 respondents with complete data were analyzed by logistic regression analysis. Over $80 \%$ of males and females expressed the desire to marry and have children in the future. It was found that for both female and male respondents, the "desire to marry" was associated with currently being in a romantic relationship or having experience of sexual intercourse. On the contrary, the "desire to have children" was associated with currently being in a romantic relationship or having experience of sexual intercourse only among male respondents, and no significant association was observed among female respondents.

Conclusion: "Currently being in a romantic relationship" and "having experience of sexual intercourse" were associated with wanting to marry and have children in the future among male university students. This suggests that these may be important factors in providing a positive perception regarding having children when they attain childbearing age.
\end{abstract}

Key words: sexual behavior, marriage, having children, university student, low fertility society

\section{Introduction}

The population of Japan is both aging and declining at an unprecedented pace, and the total population has declined from a peak of 128 million in 2008 to 126.9 million in 2016, representing a decrease of more than 1 million over this pe$\operatorname{riod}^{1,2)}$. Previous studies, as well as national policies related to the low birth rate, have tended to focus on improving socioeconomic conditions. Yet, few studies have focused on

Received: February 5, 2019

Accepted: May 13, 2019

Correspondence: Mayumi Ohnishi, Department of Health Sciences, Nagasaki University Graduate School of Biomedical Sciences, 1-71 Sakamoto, Nagasaki 852-8520, Japan

E-mail: mohnishi@nagasaki-u.ac.jp

This is an open-access article distributed under the terms of the Creative Commons Attribution Non-Commercial No Derivatives (by-nc-nd) License <http://creativecommons.org/ licenses/by-nc-nd/4.0/>. the issue of current sexual reproductive health, despite this being a direct determinant of fertility behavior.

Fertility preference and intention are important factors in shaping one's future reproductive behaviors. The increasing proportions of men and women who remain childless in high-income countries have led researchers to examine the differences in the desire to remain childless across different countries. For example in Europe, it has been found that an overall average of $4.2 \%$ men and $2.9 \%$ women considered childlessness an ideal family form among adults aged 18-40 years, regardless of marital status ${ }^{3)}$. In the same age group, an average of $7.0 \%$ men and 5.2\% women among 27 European countries had the intention - at least at the time of the survey-to remain childless throughout their lives, although there were variations in the distribution between countries ${ }^{3)}$. Similarly, data collected in 2015 also showed that among unmarried Japanese people aged 18-34 years, 8.5\% men and $6.9 \%$ women reported that they did not want to have children in the future-an increase of $2.3 \%$ for men and $3.8 \%$ for women compared to data taken in $1982^{4}$ ). This represents 
a slightly higher percentage than in the European countries. Even among married couples, 3.5\% men and 5.2\% women reported having no desire to have children in the future. Economic reasons were the most common grounds given for postponing and/or limiting the number of children ${ }^{4}$. Even though the target population of these past studies comprised different age groups, it can still be deduced that the perceptions on having children among the reproductive age group in Japan may vary from that of western countries.

As for marriage, postponement of marriage is the major contributor to the low birth rate in Japan, because childrearing outside wedlock is very rare compared to other countries $^{5)}$. The mean age at first marriage increased from 25.5 years to 29.4 years among females and from 28.2 years to 31.0 years among males between 1985 and 2015 . In 2015, $23.4 \%$ men and $14.3 \%$ women aged 50 were never married. Since the mid-1960s, the majority of marriage has been from romantic relationships rather than arranged alliances, suggesting the importance of understanding sexual and romantic relationships among unmarried people while addressing the low birth rate in Japan. It should also be noted that despite the current tendency to postpone marriage, there is insufficient awareness about the biological impact of age on fertility in the young population ${ }^{5,7-10)}$.

In the 8th National Survey on Adolescent Sexual Behavior by the Japanese Society for Sex Education, 61\% of both male and female students reported having experienced sexual intercourse in 2005, but this declined to 54\% among male students and 46\% among female students in 2011, and further to $47 \%$ among male students and $37 \%$ in female students in 2017 ${ }^{11)}$. The proportions of students with experience of dating and kissing have similarly declined. According to the 2016 report of the National Fertility Survey-a survey conducted every five years by the National Institute of Population and Social Security Research - the proportion of single adults with no experience of sexual intercourse had increased since 2005 . The survey reported that in 2015, over $72 \%$ of never-married 18 and 19 year olds had never had sexual relations ${ }^{12)}$. While $26.4 \%$ British and $29.2 \%$ French young people aged 18 and 19 years old reported never having had sex, this is a small proportion compared to Japanese young people of the same age $\mathrm{e}^{13)}$.

To address the paucity of evidence in this area, we conducted a cross-sectional study to assess current sexual attitudes and behaviors, as well as perceptions and beliefs regarding romantic partnerships, marriage, and having children, among Japanese university students. The present study will assess factors associated with the desires to marry and have children in the future, focusing on experiences of romantic and sexual relationships. The findings will help to elucidate the behaviors of young unmarried people, who are the key target of government policies, to address the low birth rate in $\operatorname{Japan}^{14)}$.

\section{Methods}

\section{Study participants}

This study took place in A University located in the capital city of a Japanese prefecture. One of A University's missions is "To serve as the driving force of regional revitalization in the age of globalization as a community-based university by staying close to the needs of the community", thereby contributing to community development and serving society ${ }^{15}$. About $40 \%$ of the university's undergraduate students are from the prefecture in which A University is located, and another $40 \%$ are from neighboring prefectures. Although most statistical information related to sexual attitudes and behaviors demonstrates the nationwide average of Japan, the authors expected to assess if there would be local characteristics from this study.

The total number of undergraduate students at A University is below 10,000. Out of 3,221 male and female students who were registered as first- and second-year students, a total of 2,691 active (i.e. not on leave) students in the target subject classes from all schools and faculties of A University were invited to participate in this study. First- and second-year students were selected because the authors estimated that there would be no significant gender difference regarding sexual experiences among them. This supposition was based on the results of the 8th National Survey on Adolescent Sexual Behavior ${ }^{11}$, which showed that although the proportions of students with experience of dating, kissing, and having sexual intercourse was higher among female high school students than male high school students, the proportions of gender difference were replaced among university students. The authors hence expected that the first and second years would be a "transition phase" of such gender difference replacement, and there would be no significant difference regarding sexual experiences among them. In other words, first- and second-year students were targeted to examine factors related to desires to future marriage and having children among youth with similar experience rate of having romantic relationships and sexual intercourse.

The target students were divided into three groups based on their study disciplines: humanities/social sciences, medi$\mathrm{cal} /$ health-related sciences, and natural sciences/engineering.

\section{Questionnaire development}

Before the development of the questionnaire for use in the quantitative study, individual semi-structured interviews were conducted among students of similar age, and past surveys on similar topics in Japan and UK were reviewed $^{12,13,16-18)}$. The findings of the interviews were then used to develop the questionnaire for this study, taking into account the characteristics of the study population. For example, choosing appropriate terminologies used by the young generation, particularly related to sexual activities. 
The final questionnaire included items on: 1) perceptions related to romance, marriage, and childrearing; 2) experience of romantic relationships; 3) sexual experience such as kissing and intercourse; and 4) self-esteem as evaluated by the Rosenberg self-esteem scale (10-40 points) ${ }^{19,20)}$.

In Japan, it is common practice for a person to first declare their feelings to their object of affection and reach mutual agreement before entering an exclusive romantic relationship. In this respect, the question "Have you ever confessed your romantic feelings to the person you like?" was included as part of the experience of romantic relationships. In addition, the question "Have you made approaches to the person you like?" as part of the experience of seeking romantic relationships included approaches that do not directly express romantic feelings, such as requesting to be a friend via Facebook, exchanging contact information, and likewise.

\section{Data collection procedure}

A cross-sectional study was conducted employing an anonymous, self-administered, and structured questionnaire, using the online survey development software "Survey Monkey". The study was designed so that students could complete the online questionnaire, after receiving appropriate explanation, in the classrooms and/or in their free time. They used their own personal electronic devices (smartphones/laptops/tablets), which they brought to each class as a requirement for attendance to each lecture. Male and female first- and second-year undergraduate students of A University were contacted through compulsory courses taught between December 2016 and February 2017. The only exception was first year students from the Faculty of Education (about 240 students), due to lack of permission from the course organizers since their curriculum during the study period was too tightly scheduled for the students to participate in this study. We identified compulsory courses taught to the students from the university curriculums and gained permission from 31 course organizers to conduct data collection before, during, or after one of the classes. Thirty-one courses were identified, ensuring there was no double registration by the same students. We were able to reach a total of 2,691 students, accounting for $80 \%$ of all students in the first and second years. Compulsory courses were selected to minimize bias from absenteeism, as these modules have a higher attendance rates than elective modules.

The researchers in this study visited each of the classes and explained the study's aim, methods, and confidentiality, verbally and with a written information sheet to the students. This was done either before, at the end of, or after a class, depending on availability of time, because previous studies suggested that administration of a questionnaire in the classroom might increase its response rate ${ }^{21}$. Details of how to access the online survey using the quick response
(QR) codes and URLs (uniform resource identifiers) in the information sheet and on A University's online learning management system, or by e-mail (depending on the agreement with the course organizer) were also clearly explained to the students. The questionnaire did not allow participants access from the same device more than once. In addition, students were requested not to participate in the study more than once, both verbally and on the information sheet. Consent was elicited on the first page of the online survey. Participants could skip questions that they did not wish to answer and could stop at any time if they wished to withdraw from the survey.

\section{Analysis}

We first performed a descriptive analysis of the students' demographic characteristics and the main outcomes, i.e. desire to marry and have children in the future, as well as experiences of romantic relationships. In the analysis, "no" and "don't know" responses regarding desire to marry and to have children were combined into one category. The factors associated with desire to marry and have children were analyzed by $\chi^{2}$ test or $t$-test and logistic regression analysis using SPSS version 22 .

\section{Ethical considerations}

This study was conducted after obtaining approval from the ethics committee of Nagasaki University Graduate School of Biomedical Sciences (approval number: 16101339) and the Institutional Review Board of the London School of Hygiene \& Tropical Medicine.

\section{Results}

A total of 1,264 students accessed the online survey. International students, respondents aged 22 years and older, students who were married and/or ever had children, and surveys missing values necessary for the analysis in this paper were excluded, leaving a total of 815 respondents for the analysis. Table 1 shows the demographic characteristics of the study participants that were included in the statistical analysis. The total numbers of students involved in paid casual or part-time work and those involved in extracurricular activities were $650(79.8 \%)$ and $624(76.6 \%)$ respectively. The mean \pm SD (standard deviation) scores on the Rosenberg self-esteem scale (10-40 points) were significantly different between female and male respondents (26.6 \pm 1.8 vs. $26.3 \pm 2.2$, respectively; $P=0.023, t$-test). Distributions of female and male respondents varied across the three major disciplines $(P<0.001)$. Female respondents were almost equally distributed, while over $70 \%$ of male respondents were studying engineering or natural sciences.

Table 2 shows the experiences of romantic relationships, relationships with friends, desire to marry, and inclination 
Table 1 Demographic characteristics of study participants $(n=815)$

\begin{tabular}{|c|c|c|c|c|c|}
\hline & \multicolumn{2}{|c|}{ Female $(n=353)$} & \multicolumn{2}{|c|}{ Male $(n=462)$} & \multirow{2}{*}{$P$-value } \\
\hline & $n$ & $\%$ & $n$ & $\%$ & \\
\hline \multicolumn{6}{|l|}{ Academic category } \\
\hline Humanities/Social sciences & 124 & 35.1 & 64 & 13.9 & \multirow[t]{3}{*}{$<0.001$} \\
\hline Medical/Health-related sciences & 109 & 30.9 & 68 & 14.7 & \\
\hline Natural sciences/Engineering & 120 & 34.0 & 330 & 71.4 & \\
\hline \multicolumn{6}{|l|}{ Part-time job } \\
\hline Yes & 294 & 83.3 & 356 & 77.1 & \multirow[t]{2}{*}{0.028} \\
\hline No & 59 & 16.7 & 106 & 22.9 & \\
\hline \multicolumn{6}{|l|}{ Participation in extracurricular activities } \\
\hline Yes & 269 & 76.2 & 355 & 76.8 & \multirow[t]{2}{*}{0.832} \\
\hline No & 84 & 23.8 & 107 & 23.2 & \\
\hline Age $($ mean $\pm \mathrm{SD})$ & \multicolumn{2}{|c|}{$19.4 \pm 0.7$} & \multicolumn{2}{|c|}{$19.6 \pm 0.8$} & 0.001 \\
\hline Self-esteem (Rosenberg self-esteem scale scores) (mean \pm SD) & \multicolumn{2}{|c|}{$26.6 \pm 1.8$} & \multicolumn{2}{|c|}{$26.3 \pm 2.3$} & 0.023 \\
\hline
\end{tabular}

$\chi^{2}$ test or $t$-test was conducted.

Table 2 Attitudes to romantic relationships by gender $(n=815)$

\begin{tabular}{|c|c|c|c|c|c|}
\hline & \multicolumn{2}{|c|}{ Female $(n=353)$} & \multicolumn{2}{|c|}{ Male $(n=462)$} & \multirow{2}{*}{$P$-value } \\
\hline & $n$ & $\%$ & $n$ & $\%$ & \\
\hline Has a close friend of the same gender & 349 & 98.9 & 444 & 96.1 & 0.016 \\
\hline Has a close friend of the opposite gender & 264 & 74.8 & 276 & 59.7 & $<0.001$ \\
\hline Has experience of a romantic date & 301 & 85.3 & 363 & 78.6 & 0.015 \\
\hline Has been interested in someone as a potential romantic partner & 347 & 98.3 & 447 & 96.8 & 0.167 \\
\hline Has made approaches to the person they like & 259 & 73.4 & 331 & 71.6 & 0.585 \\
\hline Has ever confessed their romantic feelings to the person they like & 211 & 59.8 & 326 & 70.6 & $<0.001$ \\
\hline Has ever being in a romantic relationship & 266 & 75.4 & 302 & 65.4 & 0.002 \\
\hline Is currently in a romantic relationship & 142 & 40.2 & 126 & 27.3 & $<0.001$ \\
\hline Has sexual experience & 222 & 62.9 & 265 & 57.4 & 0.111 \\
\hline Has experience of sexual intercourse & 121 & 34.3 & 168 & 36.4 & 0.537 \\
\hline Has desire to marry in future & 294 & 83.3 & 378 & 81.8 & 0.585 \\
\hline Has desire to have children in future ${ }^{a}$ & 248 & 80.5 & 380 & 82.3 & 0.513 \\
\hline
\end{tabular}

$\chi^{2}$ test or Fisher's exact test was conducted. ${ }^{\text {a }}$ : Only 317 female study participants responded, and there were 36 missing values.

to have children in the future, by gender. It was found that compared to female respondents, male respondents were significantly more likely to lack a close friend of the same gender ( $3.9 \%$ vs. $1.1 \%$, respectively, $P=0.016, \chi^{2}$ test), lack a close friend of the opposite gender $(40.3 \%$ vs. $25.2 \%$, respectively, $P<0.001, \chi^{2}$ test), and to have never gone out with someone in whom they were interested as a potential romantic partner (21.4\% vs. $14.7 \%$, respectively; $P=0.015, \chi^{2}$ test). Over $95 \%$ of male and female respondents reported that they had experienced being interested in someone as a potential romantic partner, and $85.3 \%$ female respondents and $78.6 \%$ male respondents had experienced a romantic date. Male respondents were significantly more likely to have confessed their love than female respondents $(70.6 \%$ vs. $59.8 \%$, respectively; $P<0.001, \chi^{2}$ test). There was no significant difference between female and male respondents in making approaches toward a person in whom they had a romantic interest, for example by sending them a friend request on social media (73.4\% vs. $71.6 \%$, respectively; $P=0.585, \chi^{2}$ test).

The reasons given for not having approached a person in whom they had a romantic interest were fear or shyness about the person finding out about their feelings, not wanting the person to have a negative opinion of them, lack of self-confidence, and not wanting to be belittled. Similarly, reasons given for not having confessed their feelings to a person in whom they had a romantic interest included fear of rejection, not wanting to affect their current relationship, not being sure of their feelings toward the person, being content with one-sided love, and choosing to wait for the person to make the first move (results not shown in Tables).

Females were more likely to have romantic relationships than males, but there was no difference in experiences of 
sexual activities by gender. Among those who were currently in a romantic relationship, 97 (68.3\%) females and 101 $(80.2 \%)$ males responded as having experience of sexual intercourse (results not shown in Tables). Additionally, there were no significant gender differences in the desire to marry ( $83.3 \%$ for females and $81.8 \%$ for males, $P=0.585, \chi^{2}$ test) or to have children $(80.5 \%$ for females and $82.3 \%$ for males, $P=0.513, \chi^{2}$ test $)$.

Table 3 shows a bivariate analysis regarding factors associated with the desire to marry and have children in the future. Among female respondents, the desire to have children decreased with age $(P=0.042$, t-test $)$, while there was no such trend among male respondents. Among male respondents, the desire to marry and have children were associated with having a part-time job $(P=0.005$ and $P<0.001$, respectively, $\chi^{2}$ test) and high self-esteem $(P=0.002$ and $P=0.008$, respectively, t-test), while no such trend was observed among female respondents. Among male respondents, currently being in a romantic relationship $(P<0.001$ and $P=0.001$, respectively, $\chi^{2}$ test $)$ and having experience of sexual intercourse $\left(P=0.001\right.$ and $P<0.001$, respectively, $\chi^{2}$ test) were associated with both the desires to marry and to have children, although there was no such clear association among female respondents.

Table 4 shows the conditions associated with the desire to marry in future, by logistic regression analysis. According to the results of bivariate analysis, model I included age, self-esteem, having a part-time job, participation in extracurricular activities, and currently being in a romantic relationship as independent variables. Model II included the same independent variables as model I, except currently being in a romantic relationship, which was replaced with having experience of sexual intercourse. Since currently being in a romantic relationship and having sexual intercourse were not correlated, analysis was conducted separately for models I and II. Among female respondents, the desire to marry in the future was significantly associated with younger age (AOR (adjusted odds ratio): $0.501 ; 95 \%$ CI (confidence interval): 0.333 , $0.752 ; P=0.001$ in model I), and currently being in a romantic relationship (AOR: $1.981 ; 95 \%$ CI: $1.057,3.712 ; P=0.033$ in model I) or having experience of sexual intercourse (AOR: 2.132; 95\% CI 1.087, 4.180; $P=0.028$ in model II). Among male respondents, there was no significant association between desire to marry and age (AOR: $1.124 ; 95 \%$ CI: 0.830 , $1.522 ; P=0.449$ in model I), but higher self-esteem (AOR: 1.167; 95\% CI: $1.052,1.296 ; P=0.004$ in model I) showed a positive association. Among male respondents, currently being in a romantic relationship (AOR: 2.984 ; 95\% CI: 1.463 , 6.086; $P=0.003$ in model I) and having experience of sexual intercourse (AOR: 2.406; 95\% CI: $1.328,4.361 ; P=0.004$ in model II) were associated with a desire to marry.

Logistic regression analysis was performed regarding the desire to have children in the future using the same mod- els (I and II) (Table 5). Among female respondents, younger age (AOR: $0.650 ; 95 \%$ CI: $0.448,0.943 ; P=0.023$ in model I) was associated with the desire to have children. However, among male respondents, higher self-esteem (AOR: 1.137; 95\% CI 1.026, 1.260; $P=0.015$ in model I), having a parttime job (AOR: 1.986; 95\% CI: 1.165, 3.385; $P=0.012$ in model I), and currently being in a romantic relationship (AOR: 2.723 ; 95\% CI: $1.333,5.564 ; P=0.006$ in model I) or having experience of sexual intercourse (AOR: 4.099; 95\% CI: $2.057,8.168 ; P<0.001$ in model II) were associated with the desire to have children in future.

As shown in Tables 4 and 5, we obtained similar results when experience of having been in a romantic relationship was used as an independent variable instead of currently being in a romantic relationship.

\section{Discussion}

The present study found that over $80 \%$ of males and females had the desire to marry and have children in the future, and that currently being in a romantic relationship and having experience of sexual intercourse were associated with wanting to marry and have children in the future among the male university students. However, among female university students, these factors were associated only with wanting to marry, but not with wanting to have children in the future.

The findings from the present study showed interesting differences between Japanese students and students in other Asian and western countries. For example, Japanese university students' desires to marry (female: $83.3 \%$; male: $81.8 \%$ ) was found to be higher compared to that among university students in Hong Kong (65\%), where the current total fertility rate is 1.2 children per woman, which is lower than in Japan. As for the desire to have children, 4.2\% female students and $4.1 \%$ male students in this study reported no desire to have children, while the percentage among university students in Hong Kong was $20 \%{ }^{22)}$. On the other hand, university students' desires to have children were found to be slightly higher in western countries such as Sweden (female: 96\%; male: 97\%) ${ }^{5}$, Denmark (female: 97\%; male: $87 \%)^{7}$ ), and USA (female: $88 \%$; male: $\left.91 \%\right)^{6}$. The results of the present study also indicated that the desires to marry and to have children in the future decreased with age among female students. One possible explanation is that teenagers often have an abstract notion that they would one day marry, while those in their early twenties start thinking in more realistic terms about jobs, working life and career plans, pushing marriage and children lower on their list of priorities.

The associations of being in a romantic relationship and having experience of sexual intercourse with wanting to marry in the future suggest that having a partner and experience of sexual intercourse - conditions that underpin mar- 
Table 3 Factors associated with desire to marry in future and desire to have children in the future $(n=815)$

\begin{tabular}{|c|c|c|c|c|c|c|c|c|c|c|}
\hline & \multicolumn{10}{|c|}{ Desire to marry } \\
\hline & \multicolumn{5}{|c|}{ Female $(n=353)$} & \multicolumn{5}{|c|}{ Male $(n=462)$} \\
\hline & \multicolumn{2}{|c|}{$\begin{array}{c}\text { Yes } \\
(n=294)\end{array}$} & \multicolumn{2}{|c|}{$\begin{array}{l}\text { No/Don't } \\
\text { know } \\
(n=59)\end{array}$} & \multirow[t]{2}{*}{$P$} & \multicolumn{2}{|c|}{$\begin{array}{c}\text { Yes } \\
(n=378)\end{array}$} & \multicolumn{2}{|c|}{$\begin{array}{c}\text { No/Don't } \\
\text { know } \\
(n=84)\end{array}$} & \multirow[t]{2}{*}{$P$} \\
\hline & $n$ & $\%$ & $n$ & $\%$ & & $n$ & $\%$ & $n$ & $\%$ & \\
\hline \multicolumn{11}{|l|}{ Academic category } \\
\hline Humanities/Social sciences & 104 & 83.9 & 20 & 16.1 & 0.646 & 55 & 85.9 & 9 & 14.1 & 0.629 \\
\hline Medical/Health-related sciences & 93 & 85.3 & 16 & 14.7 & & 56 & 82.4 & 12 & 17.6 & \\
\hline Natural sciences/Engineering & 97 & 80.8 & 23 & 19.2 & & 267 & 80.9 & 63 & 19.1 & \\
\hline \multicolumn{11}{|l|}{ Part-time job } \\
\hline Yes & 49 & 83.1 & 10 & 16.9 & 0.958 & 77 & 72.6 & 29 & 27.4 & 0.005 \\
\hline No & 245 & 83.3 & 49 & 16.7 & & 301 & 84.6 & 55 & 15.4 & \\
\hline \multicolumn{11}{|l|}{ Extracurricular activities } \\
\hline Yes & 227 & 84.4 & 42 & 15.6 & 0.321 & 296 & 83.4 & 59 & 16.6 & 0.113 \\
\hline No & 67 & 79.8 & 17 & 20.2 & & 82 & 76.6 & 25 & 23.4 & \\
\hline \multicolumn{11}{|l|}{ Current romantic relationship } \\
\hline Yes & 124 & 87.3 & 18 & 12.7 & 0.095 & 116 & 92.1 & 10 & 7.9 & $<0.001$ \\
\hline No & 170 & 80.6 & 41 & 19.4 & & 262 & 78.0 & 74 & 22 & \\
\hline \multicolumn{11}{|l|}{ Sexual intercourse } \\
\hline Yes & 107 & 88.4 & 14 & 11.6 & 0.061 & 151 & 89.9 & 17 & 10.1 & 0.001 \\
\hline No & 187 & 80.6 & 45 & 19.4 & & 227 & 77.2 & 67 & 22.8 & \\
\hline Age $($ mean $\pm \mathrm{SD})$ & \multicolumn{2}{|c|}{$19.7 \pm 0.7$} & \multicolumn{2}{|c|}{$19.4 \pm 0.8$} & 0.002 & \multicolumn{2}{|c|}{$19.6 \pm 0.8$} & \multicolumn{2}{|c|}{$19.5 \pm 0.7$} & 0.23 \\
\hline \multirow[t]{5}{*}{ Self-esteem (mean \pm SD) } & \multicolumn{2}{|c|}{$26.6 \pm 1.8$} & \multicolumn{2}{|c|}{$26.6 \pm 1.9$} & 0.931 & \multirow{2}{*}{\multicolumn{2}{|c|}{$26.5 \pm 2.1$}} & 25. & 2.9 & 0.002 \\
\hline & & & & & sire to $\mathrm{l}$ & & & & & \\
\hline & & & ale $(r$ & $353)$ & & & & $\mathrm{e}(n$ & 162) & \\
\hline & $\begin{array}{c}Y \\
(n=\end{array}$ & $\begin{array}{l}\text { s } \\
84)\end{array}$ & & & $P$ & & & $\begin{array}{r}\text { No } \\
\mathrm{k} \\
(n\end{array}$ & $\begin{array}{l}\text { on’t } \\
\text { w } \\
84)\end{array}$ & $P$ \\
\hline & $n$ & $\%$ & $n$ & $\%$ & & $n$ & $\%$ & $n$ & $\%$ & \\
\hline Academic category & & & & & & & & & & \\
\hline Humanities/Social sciences & 100 & 80.6 & 24 & 19.4 & 0.019 & 53 & 82.8 & 11 & 17.2 & 0.352 \\
\hline Medical/Health-related sciences & 96 & 88.1 & 13 & 11.9 & & 60 & 88.2 & 8 & 11.8 & \\
\hline Natural sciences/Engineering & 88 & 73.3 & 32 & 26.7 & & 267 & 80.9 & 63 & 19.1 & \\
\hline Part-time job & & & & & & & & & & \\
\hline Yes & 43 & 72.9 & 16 & 27.1 & 0.108 & 75 & 70.8 & 31 & 29.2 & $<0.001$ \\
\hline No & 241 & 82.0 & 53 & 18.0 & & 305 & 85.7 & 51 & 14.3 & \\
\hline Extracurricular activities & & & & & & & & & & \\
\hline Yes & 219 & 81.4 & 50 & 18.6 & 0.416 & 299 & 84.2 & 56 & 15.8 & 0.043 \\
\hline No & 65 & 77.4 & 19 & 22.6 & & 81 & 75.7 & 26 & 24.3 & \\
\hline Current romantic relationship & & & & & & & & & & \\
\hline Yes & 117 & 82.4 & 25 & 17.6 & 0.451 & 116 & 92.1 & 10 & 7.9 & 0.001 \\
\hline No & 167 & 79.1 & 44 & 20.9 & & 264 & 78.6 & 72 & 21.4 & \\
\hline Sexual intercourse & & & & & & & & & & \\
\hline Yes & 103 & 85.1 & 18 & 14.9 & 0.110 & 157 & 93.5 & 11 & 6.5 & $<0.001$ \\
\hline No & 181 & 78.0 & 51 & 22.0 & & 223 & 75.9 & 71 & 24.1 & \\
\hline Age (mean $\pm \mathrm{SD})$ & 19.4 & $=0.8$ & 19. & $=0.7$ & 0.042 & 19.6 & $=0.8$ & 19. & 0.7 & 0.075 \\
\hline Self-esteem $($ mean \pm SD) & 26.7 & $=1.8$ & 26. & $=1.9$ & 0.443 & 26.4 & $=2.3$ & 25 & 2.4 & 0.008 \\
\hline
\end{tabular}

$\chi^{2}$ test or t-test was conducted. 
Table 4 Conditions associated with desire to marry in the future $(n=815)$

\begin{tabular}{|c|c|c|c|c|c|c|c|c|c|c|c|c|}
\hline & \multicolumn{6}{|c|}{ Model I } & \multicolumn{6}{|c|}{ Model II } \\
\hline & \multicolumn{3}{|c|}{ Female $(n=353)$} & \multicolumn{3}{|c|}{ Male $(n=462)$} & \multicolumn{3}{|c|}{ Female $(n=353)$} & \multicolumn{3}{|c|}{ Male $(n=462)$} \\
\hline & AOR & $95 \% \mathrm{CI}$ & $P$ & AOR & $95 \% \mathrm{CI}$ & $P$ & AOR & $95 \% \mathrm{CI}$ & $P$ & AOR & $95 \% \mathrm{CI}$ & $P$ \\
\hline Age $^{b}$ & 0.501 & $0.333,0.752$ & 0.001 & 1.124 & $0.830,1.522$ & 0.449 & 0.503 & $0.335,0.757$ & 0.001 & 1.151 & $0.850,1.558$ & 0.363 \\
\hline Self-esteem ${ }^{b}$ & 0.977 & $0.836,1.143$ & 0.775 & 1.167 & $1.052,1.296$ & 0.004 & 0.977 & $0.836,1.142$ & 0.774 & 1.172 & $1.058,1.298$ & 0.002 \\
\hline Yes & 1.150 & $0.528,2.505$ & 0.725 & 1.641 & $0.959,2.806$ & 0.071 & 1.128 & $0.517,2.459$ & 0.762 & 1.595 & $0.929,2.739$ & 0.091 \\
\hline \multicolumn{13}{|c|}{$\begin{array}{l}\text { Participation in extracur- } \\
\text { ricular activities (ref: no) }\end{array}$} \\
\hline Yes & 1.262 & $0.663,2.402$ & 0.478 & 1.468 & $0.848,2.542$ & 0.171 & 1.219 & $0.639,2.324$ & 0.548 & 1.423 & $0.824,2.460$ & 0.206 \\
\hline \multicolumn{13}{|c|}{$\begin{array}{l}\text { Current romantic } \\
\text { relationship (ref: no) }\end{array}$} \\
\hline \multicolumn{13}{|c|}{$\begin{array}{l}\text { Experience of sexual } \\
\text { intercourse (ref: no) }\end{array}$} \\
\hline Yes & & & & & & & 2.132 & $1.087,4.180$ & 0.028 & 2.406 & $1.328,4.361$ & 0.004 \\
\hline
\end{tabular}

Logistic regression analysis was conducted. ' : continuous variables.

Table 5 Conditions associated with desire to have children in the future $(n=815)$

\begin{tabular}{|c|c|c|c|c|c|c|c|c|c|c|c|c|}
\hline & \multicolumn{6}{|c|}{ Model I } & \multicolumn{6}{|c|}{ Model II } \\
\hline & \multicolumn{3}{|c|}{ Female $(n=353)$} & \multicolumn{3}{|c|}{ Male $(n=462)$} & \multicolumn{3}{|c|}{ Female $(n=353)$} & \multicolumn{3}{|c|}{ Male $(n=462)$} \\
\hline & AOR & $95 \% \mathrm{CI}$ & $P$ & AOR & $95 \% \mathrm{CI}$ & $P$ & AOR & $95 \% \mathrm{CI}$ & $P$ & AOR & $95 \% \mathrm{CI}$ & $P$ \\
\hline Age $^{b}$ & 0.65 & $0.448,0.943$ & 0.023 & 1.243 & $0.914,1.689$ & 0.165 & 0.641 & $0.441,0.932$ & 0.02 & 1.263 & $0.923,1.727$ & 0.114 \\
\hline Self-esteem ${ }^{b}$ & 1.052 & $0.908,1.218$ & 0.501 & 1.137 & $1.026,1.260$ & 0.015 & 1.048 & $0.905,1.215$ & 0.532 & 1.152 & $1.038,1.279$ & 0.008 \\
\hline \multicolumn{13}{|c|}{ Part-time job (ref: no) } \\
\hline Yes & 1.914 & $0.977,3.749$ & 0.058 & 1.986 & $1.165,3.385$ & 0.012 & 1.853 & $0.944,3.637$ & 0.073 & 1.763 & $1.027,3.026$ & 0.04 \\
\hline \multicolumn{13}{|c|}{$\begin{array}{l}\text { Participation in extracur- } \\
\text { ricular activities (ref: no) }\end{array}$} \\
\hline Yes & 1.241 & $0.677,2.276$ & 0.484 & 1.64 & $0.947,2.838$ & 0.077 & 1.213 & $0.660,2.231$ & 0.533 & 1.604 & $0.921,2.794$ & 0.095 \\
\hline \multicolumn{13}{|c|}{$\begin{array}{l}\text { Current romantic } \\
\text { relationship (ref: no) }\end{array}$} \\
\hline \multicolumn{13}{|c|}{$\begin{array}{l}\text { Experience of sexual } \\
\text { intercourse (ref: no) }\end{array}$} \\
\hline Yes & & & & & & & 1.633 & $0.890,2.999$ & 0.113 & 4.099 & $2.057,8.168$ & $<0.001$ \\
\hline
\end{tabular}

Logistic regression analysis was conducted. ${ }^{\text {b }}$ : continuous variables.

ried life - may contribute to the desire to marry, though the causality cannot be inferred. Results showed that currently being in a romantic relationship and having experience of sexual intercourse were associated with the desire to have children in the future only among men. In addition, being in a romantic relationship and having sexual intercourse were roughly correlated among male respondents, but not among female respondents in this study. These differences may be attributed to the fact that women tend to be more circumspect with regard to balancing life and career with pregnancy and childbirth than men. Both non-regular as well as regular Japanese female workers experience high levels of responsibility and excessive workload in the workplace and at home ${ }^{23)}$. Although there may be limited opportunities for the general population, including university students, to be aware of the findings of such academic research, the media have disseminated the idea that it is difficult for women to have a child in a nursery school and continue working. Another study conducted at the same university as this study has in fact indicated that female students were more likely to give a "yes" response to the statements "there is a possibility that I will be unable to realize what I want to do be- 
cause of childrearing" and "I am worried that having a child may hinder continuing to work" compared to male students $\left(P=0.02\right.$ and $P=0.03$, respectively, $\chi^{2}$ test $)$. However, there was no significant difference between genders regarding intentions for women/female partners to continue working after marriage and childbirth ${ }^{24}$. As mentioned in the previous study published 20 years ago ${ }^{25)}$, career interruption still remains one of the major obstacles to marriage among young Japanese unmarried women. A study performed in Hong Kong also indicated that "not finding the right partner" (68\%) and "pursuit of career aspirations" (49\%) were major potential obstacles to parenthood ${ }^{22}$.

In Japan, the proportion of births to unmarried women $(2.1 \%)$ is markedly lower than in other countries (USA: 40.6\%; France: $52.6 \%$; Sweden: $54.7 \%$ ), and there persists the social norm that marriage should be a prerequisite for having children ${ }^{26}$. However, such traditional values and social norms regarding marriage and the form of family and employment may differ between generations ${ }^{27}$. The sociocultural backgrounds of Japan and western countries are different, even though Japan's economy is as large as that of western countries. There are underlying social norms and values related to gender roles, marriage and having children in Japan that may affect the way young people think and behave with regards to romantic relationships and sexual experiences. Although the present study does not have enough information to discuss the limitations of such social norms and values in this respect, there is indication that the cultural norm has become more diverse among young people. For example, the proportion of births to unmarried women has increased from $0.8 \%$ in $1980^{28)}$, even though it is by a very small degree. Additionally, the proportion of people who agreed with "it is natural for people to get married" decreased from $45 \%$ in 1993 to $27 \%$ in 2018, and that of those who agreed that marriage should be by freedom of personal choice, increased $^{29)}$.

As for social factors examined in this study, male students with part-time jobs were more likely to express a desire to marry, although this was not statistically significant, and they were also more likely to want children. Interaction with a community outside of the university allows students to gain social and interpersonal skills, and this component may contribute to having a desire for marriage and children in the future. While higher self-esteem was significantly associated with desires to marry and to have children only among male students, it may be that those with high self-esteem are more likely to be confident with future life events, including finding a marital partner. This suggests that supporting young people to increase self-esteem may help them find a romantic or sexual partner with whom they may eventually have children. The importance of developing good self-esteem is further underscored by the finding that some students refrained from approaching potential romantic partners due to fear of rejection, apparently reflecting their desire to avoid a situation that could result in feelings of inadequacy.

This study had several limitations. First, we did not ask for details regarding romantic and sexual relationships. It is possible that many of the study participants may have been at the start of a romantic relationship, and that the concept of a "romantic relationship" may have depended on the maturity of their romantic experiences. We did not have enough information to assess how actual experiences reflected on the desire to marry and have children in the future. Second, the gender distribution of respondents in this study varied across the academic category. Females comprised only $20 \%$ of the faculties of natural sciences and engineering, and this may have affected the male students' experiences of romantic relationships and sexual intercourse, and desire to marry and have children in the future. Third, this study addressed only university students, and therefore the results cannot be extrapolated to the general population of young people in Japan, although the ratio of admittance to universities is high, reaching $49.3 \%$ in $2016^{30}$. The characteristics of members of the young population who began working and/or attending vocational training after completing high school should also be evaluated to determine whether they have different needs regarding interpersonal relationships and desires regarding marriage and having children, because their social conditions may differ from those of university students. Past studies show that the economic status of the family also affected sexual activities of the younger members. For example, although the study population age was different from this study, it has been reported that family and educational factors, such as higher socioeconomic status and better school performance, could protect against early onset of sexual activities among youth aged 13-18 years ${ }^{31)}$. Such conditions must be taken into consideration when interpreting the results of this study. Fourth, the findings of this study were from one national university located in the capital city of one prefecture in Japan, and only first- and second-year students were invited to participate, which may have resulted in a selection bias. University students in the capital and/ or metropolitan areas and/or private universities may have different characteristics from the participants of our study. Further studies are needed to determine trends regarding attitudes and behaviors to sexual, reproductive, and fertility behaviors in young populations elsewhere. Although there were several limitations, this study showed the current views of university students regarding wishes for marriage and having children in the future, and the associations with their romantic and sexual behaviors.

\section{Conclusion}

The results of this study indicated that young people who are currently engaged in a romantic relationship and have ex- 
perience of sexual intercourse are more likely to express a desire to marry in the future. Male students who routinely engage in activities other than studying, such as part-time work, reacted more positively to the possibility of marrying and having children in the future. However, in female students, the desire to have children was neither associated with their current relationship status nor their experience of sexual intercourse. These findings imply that experience of intimate relationships or working part-time was associated with the desire to marry and have children in the future, and experiencing various social situations and meeting different people increases the desire to have a family. At the same time, it is also important to accommodate a range of work and lifestyles and to prepare social conditions to help young people achieve their developmental tasks, which will be required more in non-urban communities than in metropolitan areas.

\section{Conflict of interest}

The authors have no conflicts of interest to declare.

\section{Acknowledgments}

This study was supported by Kampo Foundation, and the Institutional Strategic Support Fund of the London School of Hygiene \& Tropical Medicine and Trust Fund.

The authors are grateful to all of the students for their participation in this study and to the faculty members who collaborated with us on this study.

\section{References}

1. Ministry of Internal Affairs and Communications Statistics Japan, Outline of population estimation 2016. http://www.stat.go.jp/data/jinsui/2008np/index html. Accessed March 30, 2019 (in Japanese).

2. Ministry of Internal Affairs and Communications Information and communication white paper 2016. http://www.soumu.go.jp/johotsusintokei/whitepaper/ ja/h28/html/nc111110.html. Accessed March 30, 2019 (in Japanese).

3. Miettinen A, Szalma I. Childlessness intentions and ideals in Europe. Finn Yearb Popul Res 2014; 49: 31-55.

4. National Institute of Population and Social Security Research. The 15th basic survey on birth trend, 2015. http://www.ipss.go.jp/ps-doukou/j/doukou15/ report15html/NFS15R_html10.html\#h3 3-1-1. Accessed March 30, 2019 (in Japanese).

5. Schmidt L, Sobotka T, Bentzen JG, et al. ESHRE Reproduction and Society Task Force Demographic and medical consequences of the postponement of parenthood. Hum Reprod Update 2012; 18: 29-43. [Medline] [CrossRef]

6. Ministry of Health, Labour and Welfare. Specified Report of Vital Statistics: Specified Report of Vital Statistics in FY2016, https://www.mhlw.go.jp/english/database/db-hw/vs06.html. Accessed March 30, 2019.

7. Lampic C, Svanberg AS, Karlström P, et al. Fertility awareness, intentions concerning childbearing, and attitudes towards parenthood among female and male academics. Hum Reprod 2006; 21: 558-564. [Medline] [CrossRef]

8. Peterson BD, Pirritano M, Tucker L, et al. Fertility awareness and parenting attitudes among American male and female undergraduate university students. Hum Reprod 2012; 27: 1375-1382. [Medline] [CrossRef]

9. Sørensen NO, Marcussen S, Backhausen MG, et al. Fertility awareness and attitudes towards parenthood among Danish university college students. Reprod Health 2016; 13: 146. [Medline] [CrossRef]

10. Virtala A, Vilska S, Huttunen T, et al. Childbearing, the desire to have children, and awareness about the impact of age on female fertility among Finnish university students. Eur J Contracept Reprod Health Care 2011; 16: 108-115. [Medline] [CrossRef]

11. Japanese Society for Sex Education. Report of the 8th National Survey on Adolescent Sexual Behavior. Tokyo, Shogakukan Inc., 2018 (in Japanese).

12. National Institute of Population and Social Security Research. 15th National Fertility Survey. http://www.ipss.go.jp/ps-doukou/j/doukou15/NFS15_gaiyou. pdf. Accessed March 30, 2019 (in Japanese).

13. Scott R. Understanding differences in conception and abortion rates among under 20s in Britain and France: Examining the role of disadvantage. PhD thesis, London School of Hygiene \& Tropical Medicine. 2017. DOI: 10.17037/PUBS.03482688 http://researchonline.1shtm.ac.uk/3482688/. Accessed March $30,2019$.

14. Cabinet Office, White Paper on the Low Birth-rate Society (full version). http://www8.cao.go.jp/shoushi/shoushika/whitepaper/measures/w2015/27pdfhonpen/27honpen.html. Accessed March 30, 2019 (in Japanese).

15. Nagasaki University http://www.nagasaki-u.ac.jp/en/about/philosophy/index.html. Accessed March 30, 2019

16. Bongaarts J. A framework for analyzing the proximate determinants of fertility. Popul Dev Rev 1978; 4: 105-132 (in Japanese). [CrossRef]

17. Japan Family Planning Association. Report of the 7th Survey on Men and Women's Lifestyles and Attitudes. Tokyo, 2015 (in Japanese).

18. Mercer CH, Tanton C, Prah P, et al. Changes in sexual attitudes and lifestyles in Britain through the life course and over time: findings from the National Surveys of Sexual Attitudes and Lifestyles (Natsal). Lancet 2013; 382: 1781-1794. [Medline] [CrossRef]

19. Uchida T, Ueno T. Reliability and validity of the Rosenberg self esteem scale: using the Japanese version of the RSES by Mimura \& Griffiths. Annual Bulletin, Graduate School of Education. Tohoku University 2010; 58: 257-266.

20. Schmitt DP, Allik J. Simultaneous administration of the Rosenberg Self-Esteem Scale in 53 nations: exploring the universal and culture-specific features of global self-esteem. J Pers Soc Psychol 2005; 89: 623-642. [Medline] [CrossRef]

21. Nulty DD. The adequacy of response rates to online and paper surveys: what can be done? Assess Eval High Educ 2008; 33: 301-314. [CrossRef]

22. Chan $\mathrm{CH}$, Chan $\mathrm{TH}$, Peterson BD, et al. Intentions and attitudes towards parenthood and fertility awareness among Chinese university students in Hong Kong: a comparison with Western samples. Hum Reprod 2015; 30: 364-372. [Medline] [CrossRef]

23. Inoue M, Nishikitani M, Tsurugano S. Female non-regular workers in Japan: their current status and health. Ind Health 2016; 54: 521-527. [Medline] [CrossRef] 
24. Nishihara M, Tanaka J, Ohnishi M. A study on desire to marry, continue working and image of childrearing among university students (Daigakusei-no kekkon-to shigotokeizokukibou oyobi ikuji-image-ni taisuru ichikousatsu), Japanese Journal of Public Health 2017: 64(10 special appendix): 471. (in Japanese).

25. Ho J, Sato R, Muto T. Factors that influence a woman's choice to marry and give birth - based on a survey of attitudes toward marriage, birth, child rearing, care of the elderly, and employment. Juntendo Medical Journal 1999; 44: 423-433. [CrossRef]

26. Ministry of Health Labour and Welfare. Overview of the National Basic Life Survey 2016. Tokyo, 2016. http://www.mhlw.go.jp/toukei/saikin/hw/ktyosa/k-tyosa16/d1/16.pdf. Accessed March 30, 2019 (in Japanese).

27. Shinohara S. Changes in attitudes toward marriage in Japan: analysis using the JGSS cumulative data 2000-2010, Japanese General Social Surveys Research Series 12. 2012; 81-92. (in Japanese) http://jgss.daishodai.ac.jp/english/research/monographs/jgssm12/jgssm12_07.pdf (accessed 30 Mar 2019).

28. Ministry of Health and Labour and Welfare Specified Report of Vital Statistics: Specified Report of Vital Statistics in FY1980. https://www.e-stat.go.jp/ stat-search/files?page $=1 \&$ layout $=$ datalist $\&$ toukei $=00450011 \&$ tstat $=000001028897 \&$ cycle $=7 \&$ year $=19800 \&$ month $=0 \&$ tclass $1=000001053058 \&$ tclass $2=$ $00001053061 \&$ tclass3=000001053064. Accessed April 6, 2019 (in Japanese).

29. Nippon Hoso Kyokai. The 10th survey of Japanese perception 2018, https://www.nhk.or.jp/bunken/research/yoron/pdf/20190107_1.pdf. Accessed April 6, 2019 (in Japanese).

30. Ministry of Education Culture, Sports, Science and Technology. School basic survey 2016 (Fixed values). http://www.mext.go.jp/component/b_menu/ other/_ icsFiles/afieldfile/2016/12/22/1375035 1.pdf. Accessed March 30, 2019 (in Japanese).

31. Lammers C, Ireland M, Resnick M, et al. Influences on adolescents' decision to postpone onset of sexual intercourse: a survival analysis of virginity among youths aged 13 to 18 years. J Adolesc Health 2000; 26: 42-48. [Medline] [CrossRef] 